\title{
The Influence Factors Research of Music Therapy and Information Technology in High Blood Pressure Patients' Bad Emotions and Cognition
}

\author{
Liu Yan ${ }^{1}$, Wu Ya-fen ${ }^{2}$, Wan Li-li ${ }^{3^{*}}$ \\ ${ }^{1.3}$ College of Humanities,Jiangxi University of Traditional Chinese Medicine, Nanchang Jiangxi 330004, \\ China \\ 2. Scientific Research Center, Jiangxi University of Traditional Chinese Medicine, Nanchang Jiangxi \\ 330004, China \\ 398245959@QQ.COM*
}

Keywords: Music therapy; Information technology; Patients with high blood pressure; Bad mood; Cognitive ability

\begin{abstract}
This paper's objective is to study the influence of music therapy and information technology on bad feelings and cognition of high blood pressure patients. The method adopted is to make a retrospective analysis of 100 cases medical records of patients with high blood pressure admitted in a hospital. Apply routine nursing care to control group patients with high blood pressure, while apply music therapy and information technology to observation group of patients with high blood pressure. Compare bad emotions and cognitive ability of the patients with high blood pressure in two groups. The results are (1) patients' anxiety and depression score in observation group, compared to those of control group, are significantly lower. $\mathrm{P}<0.05$, which means it has statistical significance; (2) patients' mild cognitive impairment in observation group gradually increases from $20 \%$ before treatment to $60 \%$. Patients' mild cognitive impairment in control group rises from $20 \%$ before treatment to $32 \%$. The cognitive situation improvement of high blood pressure patients in observation group, compared to that of control group, is significantly better. $\mathrm{P}<$ 0.05. It means that there is statistical significance. (3) from the blood pressure assess result comparison of two groups' patients with high blood pressure before treatment, $\mathrm{P}>0.05$. There is no statistical significance. After treatment, blood pressure assess result comparison shows that observer group is better. $\mathrm{P}<0.05$. It means that there is statistical significance. It is safe to conclude that the application of music therapy and information technology in patients with high blood pressure can not only effectively relieve patients' bad feelings, but also improve the patient's cognitive ability. Therefore it has certain application value and is worthy of clinical popularization and application.
\end{abstract}

In recent years, population aging speed is accelerating, which gradually increases prevalence of patients with high blood pressure. The clinical effective treatment and management of patients with high blood pressure are always the focus of particular concern in medicine [1]. Patients with high blood pressure are often accompanied by all sorts of bad moods, which have direct influence on patients' life. At the same time, patients have poor cognitive ability. This research has a certain value through music therapy and information technology management to patients with high blood pressure. The overall report is as follows:

\section{DATA AND METHODS}

\section{A. General information}

There are 100 cases of patients with high blood pressure are treated in a hospital, and divide them randomly into control group and observation group. Among the 50 patients in control group, 30 cases are male and 20 cases are women. Their ages are between 42 to 79 , and the average age is (53.6 \pm 2.9$)$. Among the 50 cases in observation group, 28 cases are men and 22 cases are women. Their ages are between 43 to 76, and the average age is (54.1 \pm 1.9 ). Comparing and analyzing the general information of patients with high blood pressure in two groups, $\mathrm{P}>0.05$. There is no 
statistical significance, and they are comparable.

\section{B. Method}

Apply routine nursing to the patients with high blood pressure in control group. Provide the patients with normal heart rate and blood pressure monitoring. Give the patients' health education guidance and timely illustrate knowledge of blood pressure. Guide the patients to correctly use drugs, and analyze the name and effect of the drugs. Combined with diet adjustment, ensure that patients have a good work and rest habits and have stable blood pressure. Eliminate patients' fears in a timely manner as far as possible and give patients educational propaganda on a regular basis, and hand out health brochures for free. Apply music therapy and information technology to observation group patients with high blood pressure on the basis of routine care. In patient's ward, install music system. Nursing managers operate it and provide slow and light music to timely relieve melancholy mood of the patients and ease the pain of the patients timely. The application of music therapy is once per day and each time lasts for $30 \mathrm{~min}$. With the application of information technology management methods, take statistics about the basic condition of the patients, lifestyle and blood pressure check. Combined with basic management model of health management information platform, automatically upload the measured data. Send message alerts to patients' families. Once there is abnormal situation in the patient's blood pressure, send the message via telephone and the Internet in time to guide the healthy treatment of the patients. Compare and analyze bad emotions and cognitive ability of the patients with high blood pressure in two groups.

\section{Evaluation standard}

Evaluate patients' bad mood in combination with anxiety self-assessment scale and depression self-rating scale. There are 20 SAS programs and 20 SDS projects. Use the method of 1- 4 grade score, and the anxiety score is $\geq 50$ points, and depression score is $\geq 53$ points. Patients' depression and anxiety levels have direct proportion relationships with the scores. Patients' cognition evaluation adopts indexes like severe cognitive impairment, moderate cognitive impairment and mild cognitive impairment.

D. Statistical methods

Apply statistical software SPSS18.0 for data analysis. Use $t$ test for data measurement. Use $\mathrm{X}^{2}$ test for counting data. $\mathrm{P}<0.05$. It means that there is statistical significance.

\section{RESULTS}

A. Compare anxiety depression score results of two groups' high blood pressure patients

The comparison of anxiety depression score of patients with high blood pressure in two groups is shown in Table 1. The anxiety and depression scores results of patients with high blood pressure in observation group, compared to control group, is significantly lower. $\mathrm{P}<0.05$. It means there is statistical significance.

Table 1 The comparison of anxiety depression score of patients with high blood pressure in two groups

\begin{tabular}{|c|c|c|c|c|c|}
\hline \multirow[t]{2}{*}{ Group } & \multirow[t]{2}{*}{ Cases } & \multicolumn{2}{|c|}{ SDS } & \multicolumn{2}{|c|}{ SAS } \\
\hline & & $\begin{array}{l}\text { Before } \\
\text { treatment }\end{array}$ & $\begin{array}{c}\text { After } \\
\text { treatment }\end{array}$ & $\begin{array}{l}\text { Before } \\
\text { treatment }\end{array}$ & $\begin{array}{c}\text { After } \\
\text { treatment }\end{array}$ \\
\hline $\begin{array}{l}\text { Control } \\
\text { group }\end{array}$ & 50cases & $55.7 \pm 4.9$ & $51.7 \pm 2.2$ & $57.2 \pm 4.9$ & $53.1 \pm 2.9$ \\
\hline $\begin{array}{l}\text { Observation } \\
\text { group }\end{array}$ & 50cases & $54.2 \pm 3.5$ & $46.1 \pm 2.4$ & $56.2 \pm 4.1$ & $49.5 \pm 2.8$ \\
\hline $\mathrm{t}$ & & 0.145 & 5.236 & 0.521 & 5.852 \\
\hline $\mathrm{P}$ & & $>0.05$ & $<0.05$ & $>0.05$ & $<0.05$ \\
\hline
\end{tabular}


B. Compare cognitive improvement status of the patients with high blood pressure in two groups The comparison of cognitive improvement status of the patients with high blood pressure in two groups is shown in Table 2. Patients with mild cognitive impairment in observation group gradually increases from $20 \%$ to $60 \%$. $20 \%$ of the control group in patients with mild cognitive impairment have before rising to $32 \%$, the cognitive situation improvement of patients with high blood pressure in observation group, compared to control group, is significantly better. $\mathrm{P}<0.05$, which means there is statistical significance.

Table 2 The comparison of cognitive improvement status of the patients with high blood pressure in two groups

\begin{tabular}{|c|c|c|c|c|c|}
\hline Group & Cases & & $\begin{array}{l}\text { Severe cognitive } \\
\text { impairment }\end{array}$ & $\begin{array}{l}\text { Moderate } \\
\text { cognitive } \\
\text { impairment }\end{array}$ & $\begin{array}{l}\text { Mild cognitive } \\
\text { impairment }\end{array}$ \\
\hline \multirow[t]{2}{*}{$\begin{array}{l}\text { Control } \\
\text { group }\end{array}$} & 50cases & $\begin{array}{l}\text { Before } \\
\text { treatment }\end{array}$ & 22cases $(44 \%)^{*}$ & $18 \operatorname{cases}(36 \%)^{*}$ & 10 cases $(20 \%)^{*}$ \\
\hline & & $\begin{array}{c}\text { After } \\
\text { treatment }\end{array}$ & 18 cases $(36 \%)^{* *}$ & $\begin{array}{l}\text { 16cases } \\
(32 \%)^{* *}\end{array}$ & 16 cases $(32 \%)^{* *}$ \\
\hline \multirow[t]{2}{*}{$\begin{array}{l}\text { Observati } \\
\text { on group }\end{array}$} & 50cases & $\begin{array}{l}\text { Before } \\
\text { treatment }\end{array}$ & 20cases（40\%） & 20 cases $(40 \%)$ & 10cases（20\%） \\
\hline & & $\begin{array}{l}\text { After } \\
\text { treatment }\end{array}$ & 10cases（20\%） & 10 cases $(20 \%)$ & 30cases（60\%） \\
\hline
\end{tabular}

Note: compare * and **. $\mathrm{P}<0.05 ; *$ compare with observation group, $\mathrm{P}>0.05$;

C. The comparison of blood pressure assess results of patients with high blood pressure in two groups

The comparison of blood pressure assess results of patients with high blood pressure in two groups is shown in Table 3. The comparison of blood pressure assess results of patients with high blood pressure in two groups before treatment shows $\mathrm{P}>0.05$, so there is no statistical significance. The comparison of blood pressure assesses results of patients with high blood pressure in two groups after treatment shows that observer group is better. $\mathrm{P}<0.05$, so there is statistical significance.

Table 3 The comparison of blood pressure assess results of patients with high blood pressure in two groups (mmHg)

\begin{tabular}{cccc}
\hline Group & Cases & Before treatment & After treatment \\
\hline Control group & 50cases & $147.25 \pm 5.23$ & $134.52 \pm 7.58$ \\
Observation group & 50 cases & $148.85 \pm 7.04$ & $122.54 \pm 4.59$ \\
$\mathrm{t}$ & & 0.529 & 5.632 \\
$\mathrm{P}$ & $>0.05$ & $<0.05$ \\
\hline
\end{tabular}

\section{DISCUSSION}

High blood pressure, a kind of chronic disease, has longer treatment time and complex treatment process, so patients have great psychological burden in treatment process. Zhou Bi [2] stated that patient's clinical treatment need effective nursing treatment to timely adjust patients' bad moods and ensure constant patients recover in The impact of Music Treatment on Pregnancy-induced Hypertension and Anxiety State. Zhang Luying [3] argued that, in clinical treatment of patients with 
high blood pressure, there is the need to adjust the routine of life of patients timely and keep stable blood pressure of patients. Zhou Bi [4] thought that the application of music therapy in patients with high blood pressure need to make sure that patients have clever and cheerful rhythm to timely adjust patients negative emotions and relieve patients' pain. Wu Lifang [5] and others thought that we should regularly monitor patients' heart rate and blood pressure and make health education guidance for patients. Timely illustrate high blood pressure knowledge and guide the patients to correctly use drugs. The drug name and effect should be analyzed. Song Yongquan [6] thought that high blood pressure patients need to make diet adjustment and ensure that patients have good sleep habits. Guarantee that patients have stable blood pressure and eliminate their fears in a timely manner as far as possible. Make educational propaganda to patients on a regular basis and hand out healthy brochures for free. Zhang Xiangyun [7] installed music system in patient's ward. The nursing managers operated it and provided slow and light music to timely relieve melancholy mood of the patients. Ease the pain of the patients timely. The application of music therapy is once per day and each time is for $30 \mathrm{~min}$. Lei Xiaohong [8] combined information technology management methods. Based on the inspection situation of basic situation, life style and blood pressure of patients combine with basic management model of health management information platform and automatically upload the measured data. Send message alerts to patients' families. Once the blood pressure of patients is abnormal, timely inform the families via telephone and the Internet.

This research studies patients with high blood pressure by applying music therapy and information technology management, and the results show that anxiety and depression scores of patients with high blood pressure in observation group, compared to that of control group, is significantly lower. $\mathrm{P}<0.05$, so there is statistically significant; the cognitive situation of patients with high blood pressure in observation group, compared to that of control group, is significantly better. $\mathrm{P}<0.05$, so there is statistical significance. Compare blood pressure assessment result of patients with high blood pressure in two groups before the treatment. $\mathrm{P}>0.05$, so there is no statistical significance. Compare blood pressure assessment result of patients with high blood pressure in two groups after the treatment. Observer group is better. $\mathrm{P}<0.05$, so there is statistical significance. It is visible that the application of music therapy and information technology to patients with high blood pressure can not only effectively relieve patients' bad feelings, but also improve patient's cognitive ability. The research results are mostly according to what reported in related literature [9-10]. This study not only carefully analyzes many years clinical experience, but analyzes the actual situation in our hospital at the same time. The study deficiencies still need improvement.

In all, the application of music therapy and information technology to patients with high blood pressure can not only effectively relieve patients' bad feelings, but also improve patient's cognitive ability. It has certain application value and is worthy of clinical popularization and application.

\section{REFERENCE}

[1] Hou Caifang. Music treatment effect on high blood pressure patients' anxiety and blood pressure treatment [J]. Journal of Nursing Research, 2014, 28 (7) : 838-839.

[2] Zhou Bi, Lin Zhimei, Lin Qiuqiong. Music treatment influence on postpartum hypertension and anxious state in patients with pregnancy [J]. Chinese Journal of Modern Nursing, 2013, 12 (25) : 3056-3058.

[3] Zhang Luying, Sui Xiangmei. 32 cases analysis of applying intelligent feedback type music to relax senile hypertension associated with depression anxiety [J]. Journal of Medical Frontier, 2012, $11(2): 218$.

[4] Zhou Bi, Yang Weifang, Zhou Meijuan. Music care application in postpartum hypertension treatment [J]. Journal of Guangdong Medical College, 2011 (6) : 701-702.

[5] Wu Lifang, Zheng Liwei. Music therapy research progress in patients rehabilitation with high blood pressure [J]. Journal of Nursing Research, 2013, 27 (21) : 2190-2192. 
[6] Song Yongquan. Li Kun. Music therapy effects on elderly patients anxiety, blood pressure and sleep patterns with high blood pressure [J]. Chinese Journal of Gerontology, 2015, 10 (7) : 1967-1968.

[7] Zhang Xiangyun. The application and effect observation of health education and music therapy in patients with high blood pressure [J]. Journal of Qilu Nursing Journal, 2011 (25) : 11-13.

[8] Lei Xiaohong, Li Chaxiang, Zhang Li. Music therapy influence on the life quality and blood pressure in patients with high blood pressure [J]. Journal of Shandong Medicine, does 2013 (20) : 90-91.

[9] Ma Liping, Yang Wenyan. Music therapy application and research progress in hypertension treatment [J]. Journal of Modern Diagnosis and Treatment, 2014, 25 (23) : 5319-5321.

[10] Wang Jiangning, Li Xiaomei. Music therapy influence on community elderly hypertensive patients anxiety and depression [J]. Journal of Nursing Research, 2013, 27 (29) : 3314-3315. 